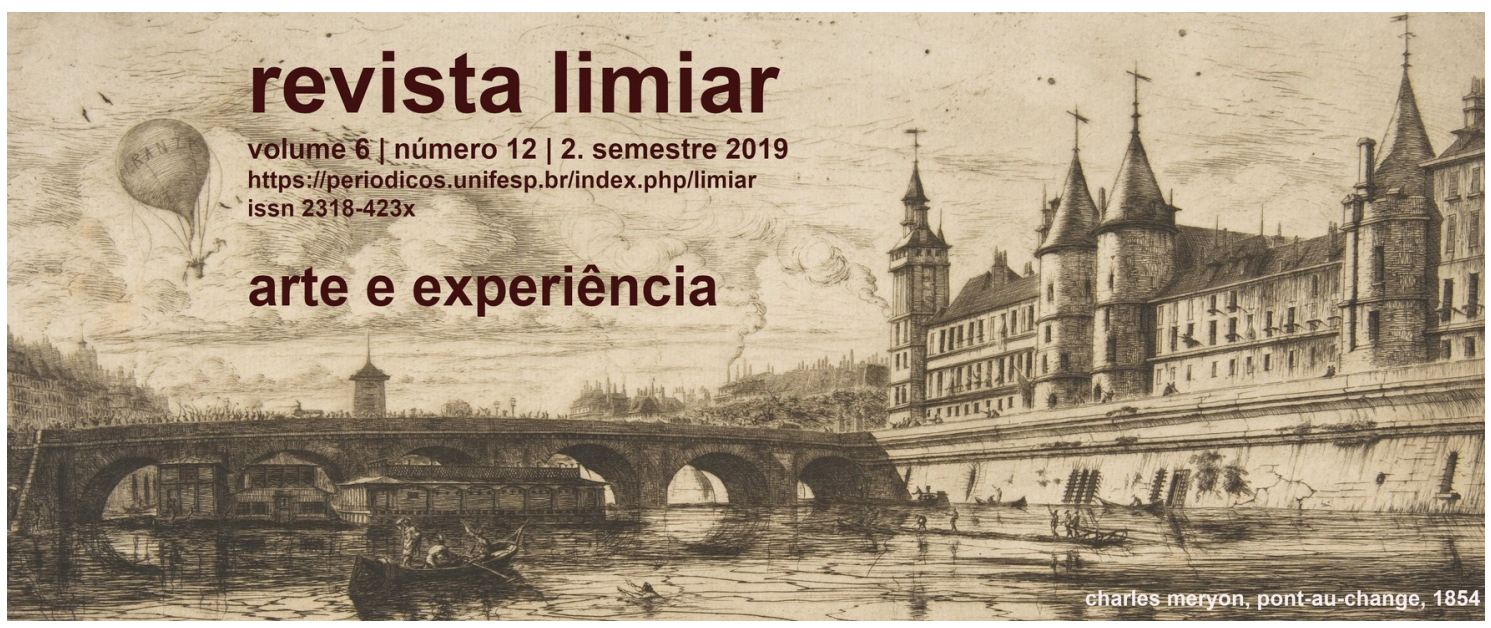

\title{
Dentro da sala escura: algumas reflexões em torno da questão do espectador a partir de Silvia Schwarzböck e Jacques Rancière
}

\section{Pedro Hussak van Velthen Ramos*}

Resumo: Este texto é uma tentativa de estabelecer alguns paralelos entre as considerações de Jacques Rancière e Silvia Schwarzböck em torno da questão do espectador no cinema. Trata-se de mostrar que há uma convergência no ponto de partida entre as duas visões quanto ao fato de que o cinema nas suas origens significou uma superação nas hierarquias entre o "bom gosto" e o "gosto vulgar ", entre a "alta" e a "baixa" cultura. No entanto, essa convergência inicial bifurca-se em duas posições diferentes no que concerne ao espectador: enquanto Rancière considera 0 cinema uma experiência democrática do ponto de vista sensível, Schwarzböck acentua a dimensão estatal do cinema. O desenvolvimento do artigo visa a tirar consequências desta contraposição.

Palavras-chave: Silvia Schwarzböck; Jacques Rancière; estética do cinema

Abstract: This text aims to establish some parallels between the considerations of Jacques Rancière and Silvia Schwarzböck around the issue of the spectator in the cinema. It is about showing that there is a convergence at the point of departure between the two visions: cinema in its origins meant an overcoming in the hierarchies between "good taste" and "vulgar taste", between "high" and "low" culture. However, this initial convergence bifurcates into two different positions regarding the spectator: while Rancière considers cinema a democratic experience from a sensitive point of view, Schwarzböck accentuates the state dimension of cinema. The development of the article aims to take the consequences of this counterposition.

Keywords: Silvia Schwarzböck; Jacques Rancière; Cinema Aesthetics

\footnotetext{
* Professor do Departamento de Filosofia da Universidade Federal Rural do Rio de Janeiro.

E-mail para contato: phussak@gmail.com.
} 
Este texto é uma tentativa de estabelecer alguns paralelos entre as considerações de Jacques Rancière e Silvia Schwarzböck em torno da questão do espectador no cinema. Professor emérito na Universidade Paris 8 , o autor francês é conhecido pelo público interessado em cinema no Brasil graças às traduções para o português de As distâncias do cinema e A Fábula cinematográfica. Silvia Schwarzböck, por seu turno, é professora da cátedra de estética do departamento de filosofia da Faculdade de Filosofia y Letras da Universidad de Buenos Aires e possui uma trajetória intelectual ligada à recepção de Theodor Adorno na Argentina: além de traduzir para o espanhol do texto de Adorno Estética (1959), ela publicou Adorno y lo político em 2008. Los monstruos más frios: estética despues del cine, o livro que será comentado aqui, foi publicado em 2017 na Argentina e ainda não tem tradução em português.

Este artigo parte de uma convergência entre as duas visões: produto da revolução industrial, o cinema foi desde os primórdios uma expressão de enorme penetração popular, desafiando as hierarquias que separavam a "alta" da "baixa" cultura. O que pretendo mostrar é que esse ponto de partida comum bifurca-se em duas concepções distintas: por um lado, uma concepção democrática e emancipadora do cinema no sentido de que proporciona ao espectador a ocasião de produzir os próprios juízos estéticos de forma independente; por outro, a ideia de que o cinema "forma" um certo tipo de percepção que vai constituir o espectador. Muito embora a leitura do artigo possa indicar um partido pela primeira posição, esclareço que o objetivo aqui é antes muito mais o de clarificar um debate.

Agradeço especialmente à professora de estética da UBA e pesquisadora do CONICET Paula Fleisner que me presenteou o livro Los monstruos más frios, cujo pensamento original cativou-me rapidamente.

\section{Pano de fundo}

O trabalho de relacionar duas visões exige sempre o estabelecimento de um pano de fundo que sirva como uma condição de possibilidade de um debate. Tal pano de fundo aqui é o problema da democratização da cultura, cuja tematização remete ao século XVIII e mais particularmente a Friedrich Schiller. Descontente com os rumos que levaram a Revolução na França ao período do terror, o poeta e pensador alemão 
defendeu uma revolução suave que deveria advir de um amplo acesso à cultura. Parte-se da crença de que uma educação da sensibilidade poderia favorecer a Aufklärung, dando portanto à cultura um aspecto funcional na organização da sociedade. Trata-se de um projeto essencialmente literário cuja realização foi possível graças à universalização da escola pública na Europa no século XIX e com popularização de um gênero literário conhecido como Romance. Para Jacques Rancière, tal popularização significou uma revolução estética na medida que o livro passou a circular de forma indiscriminada pelos diferentes estratos sociais. O livro Noite dos Proletários (1981), resultado de uma pesquisa nos arquivos do movimento operário francês de 1830, mostra como do ponto de vista sensível aqueles operários saíram, ao menos no campo da imaginação, estabelecendo uma partilha do sensível na medida em que retira ao menos subjetivamente o operário do destino social que lhe foi imposto, a saber, a servidão do trabalho mecânico. O proletário entra no "mundo burguês" graças particularmente ao contato com o romance, estabelecendo com ele um mundo sensível comum.

Tal revolução sensível ataca diretamente o problema - que se tornou tema central da disciplina que conhecemos com o nome de estética - do gosto. Filho do século XVIII, o debate em torno dessa questão encarna as próprias contradições do iluminismo em torno do problema da igualdade. Por um lado, um ideal universalista que admitia um caráter democrático do gosto; por outro, a formação do burguês como "homem de gosto" a fim de diferenciá-lo do gosto popular. É possível delimitar essas duas posições contrapondo Kant e Hume. Na Crítica da Faculdade de Julgar, em consonância com seu pensamento mais geral, Kant sustenta o universalismo do juízo de gosto ao argumentar que este nasce de um "jogo livre" entre a imaginação e o entendimento, ao passo que Hume em Do padrão do gosto sustenta que embora o gosto seja comum a todos, apenas alguns podem pela experiência refinar a sensibilidade a fim de que esta possa formar os juízos capazes de estabelecer um padrão.

A "revolução estética" de que fala Rancière produziu um novo regime de identificação das artes, o estético, que produz uma sensibilidade na qual as hierarquias do gosto são desfeitas. Trata-se de superar as hierarquias do gosto, democratizando a leitura graças à livre circulação do livro. 


\section{Cinema e ideologia}

Desta forma, Rancière considera que o cinema é uma expressão cultural que já nasce sob o signo do regime estético uma vez que o cinema é uma expressão cultural que rompe com a hierarquia que separa o "bom gosto" do "gosto vulgar", a "alta" e a "baixa" cultura, realizando do ponto de vista da sensibilidade a igualdade do espectador. O cinema proporciona uma experiência na qual o sujeito é colocado em uma sala escura junto a pessoas que ele não conhecia previamente, compartilhando a fruição estética proporcionada por uma tela grande na qual o filme é projetado. ${ }^{1}$ Essa experiência contrasta com uma certa configuração do teatro e da ópera, particularmente nos séculos XVIII e XIX, na qual o lugar ocupado pelo espectador reflete também sua condição social. Além disso, o cinema também desafia a hierarquia dos gêneros artísticos que por sua vez produzem o tipo de espectador ideal, como por exemplo a ideia de que drama sério deveria ser destinado aos estratos sociais mais altos, ao passo que a comédia aos extratos populares.

De um modo geral, o ponto de partida de Schwarzböck converge com o de Rancière quanto à compreensão de que o cinema desfaz as hierarquias do gosto. No entanto, o ponto de partida semelhante logo bifurca-se: enquanto Rancière considera que o cinema proporciona uma igualdade na situação do espectador, Schwarzböck vai em uma outra linha. O cinema em suas origens é uma arte verdadeiramente popular porque alcança amplamente a categoria social nascida com revolução industrial, a massa. No entanto, o caráter dessa arte popular, dessa expressão, é eminentemente estatal. Em outras palavras, antes da segunda guerra mundial o cinema seria basicamente um instrumento de propaganda ideológica. O cinema funciona, assim, como diria Žižek (2018), como o grande organizador do gozo coletivo. Segundo Schwarzböck, o elemento propriamente político do cinema está no fato de que em regimes totalitários as massas precisam ser mobilizadas. A massa é fria, por isso o cinema é a experiência capaz de mobilizar e direcionar os afetos para os objetivos políticos estabelecidos pelo estado.

1 Rancière aponta outro aspecto para sustentar que o cinema nasce sob o signo do regime estético: o fato de que em seus primórdios o cinema, diferente do privilégio da narrativa no regime representativo, "não contava histórias". Rancière vai desenvolver essa ideia ao mostrar que ao reintroduzir a narrativa, Hollywood contrariou a vocação inicial do cinema. Como o escopo desse artigo é a questão do espectador, a questão da narrativa não será tematizada, cf. RANCIĖRE, Jacques. Les écarts du cinema. Paris, Fabrique, 2011. 
El cine es una nueva forma de alta cultura: la cultura revolucionaria de las grandes ciudades. Pero, aún así, hay algo extremamente moderno que el cine trae a la modernidad y que no es afín a lo urbano. Lo que hace del cine un arte de la grande ciudad - el shock y, sobre todo, la recepción táctil, que requiere del espectador una atención dispersa: todo lo contrario de la contemplación de un cuadro o de la lectura de un libro -, no le permite ser, todavía, Estado. Lo pone en camino de ser arte de Estado. Pero no Estado. Ni aparato de Estado (como la familia, la escuela y la policía).

Por eso, la izquierda cinematográfica, empezando por Benjamin, ama al cine en lo que tiene de urbano, no en lo que tiene de protoestatal. Ninguna Izquierda puede amar al Estado. Nadie, en realidad, puede amar al Estado. Tampoco el fascismo. $^{2}$

Sob certos aspectos, a autora argentina vai retomar o debate dos anos 1930 sobre as possibilidades emancipatórias do cinema levado particularmente por Walter Benjamin. No texto sobre a "Obra de arte na era de sua reprodutibilidade técnica", o escritor alemão, contrariamente à "estetização da política" fascista, propõe uma "politização da arte". Além disso, ele crê que a produção do cinema, por seu caráter coletivo, supera as categorias tradicionais da estética como "gênio" e "autoria". A autora adota uma posição de matiz adorniano que vê no modo de produção cinematográfico uma expressão heterônoma porquanto industrial.

Nesse sentido, recuperando a afirmação de Lenin em 1924 de que "o cinema chegará a ser uma arte de estado, inclusive a mais importante", a autora sustenta que deve-se perceber a instrumentalização ideológica do cinema não apenas pelo fascismo, como também pelo cinema soviético. No entanto, a consideração da autora aplica-se não apenas aos regimes totalitários como também ao âmbito das democracias liberais. O cinema de Hollywood sempre possuiu o mesmo intuito de domínio ideológico no sentido da afirmação imperialista dos Estados Unidos, como bem reconheceu Adorno (1985) ao identificar nos filmes de Hollywood os mesmos truques de manipulação das emoções que os filmes de propaganda nazista.

No que toca às considerações sobre Eisenstein, a autora argentina, em grande medida, segue uma provocação feita pelo teórico alemão Boris Groys (2008), que critica a concepção recorrente nos meios de culturais de esquerda de que toda inovação formal do cinema soviético seria a prova do vigor revolucionário dos primeiros anos da revolução. Tal vigor teria sido desviado, no plano político, pelo estalinismo e pela adoção do realismo socialista como arte oficial no plano estético. Groys vai na contramão dessa visão, ao sustentar que o Encouraçado Potenkin possui

2 SCHWARZBÖCK, Silvia. Los monstruos más frios: estética después del cine. Buenos Aires: Mardulce, 2017, p. 49. 
a mesma dimensão de totalidade que o realismo socialista mais tarde vai revelar, o que portanto não diferenciaria tanto ambas expressões quanto ao seu objetivo de propaganda do regime.

Com isso, volta-se ao velho problema da ideologia no qual talvez possamos marcar a diferença entre Schwarzböck e Rancière. Por um lado, uma visão que sustenta que o cinema é a expressão do poder estatal, como em outra época a pintura da corte foi a expressão do poder estatal, como foi o caso de boa parte da obra do pintor Goya dedicado à corte espanhola.

Por outro lado, é possível dizer que uma das temáticas centrais do pensamento Rancière é justamente a de colocar em questão o efeito da ideologia sobre o espectador. Esse problema, de certa forma está no cerne de sua ruptura com seu primeiro mestre Louis Althusser. O Marxista francês dava ao intelectual de esquerda a tarefa de libertar a massa das ilusões causadas pela ideologia e acabava por produzir uma hierarquia que contraria o próprio ideal de igualdade do pensamento de esquerda. A resposta definitiva de Rancière a esse problema vem no livro $O$ mestre ignorante (2007) no qual ele argumenta que o mestre emancipador deve partir do princípio de que "todas as inteligências são iguais". O Espectador emancipado (2008) é uma tentativa de aplicar ao campo da estética esse princípio pedagógico. "Emancipar" o espectador significa não subestimar sua capacidade de compreender uma obra, apostando na sua capacidade de produzir discursos e colocá-los na arena dos debates. Assim, se faz sentido pensarmos no papel da crítica de cinema, esta deve existir não para explicar o filme para quem supostamente não tem a capacidade de compreender, mas para aumentar a partilha dos discursos. Contra a ideia de que o cinema possa "alienar" um público, o filósofo poderia argumentar que alguém que queira adotar uma determinada posição política ao assistir um filme já teria uma predisposição para adotá-la. O filme ideologicamente orientado não faz outra coisa senão reforçar a posição já adotada pelo espectador.

Nesse veio, é possível formular uma crítica rancieriana ao conceito adorniano de Indústria cultural: por um lado, porque ele revela um preconceito contra tudo o que é popular; por outro, pressupõe uma concepção de homogeneidade que não encontra eco na multiplicidade de emoções e pensamentos que uma obra pode suscitar nos sujeitos. Pode-se tirar como consequência dessas duas críticas o afastamento do pensador francês em relação ao problema da ideologia: por um lado, uma expressão cultural, de massa, como o cinema não é necessariamente ruim por ser popular; por 
outro, não é certo que todos os sujeitos são incapazes de perceber os truques de manipulação ideológica que possam estar contidos em determinados filmes. Com isso, não quero dizer que essa crítica inviabilize o conceito de Adorno no sentido da criação de todo aparato do mundo do entretenimento e de quais interesses estão em jogo, apenas que talvez seja difícil medir o efeito que a indústria cultural tem nos espectadores. Trata-se de confiar na capacidade de o espectador perceber certos elementos, certos detalhes, que escapam à tentativa de um filme estabelecer uma homogeneidade ideológica.

De uma maneira geral, Rancière quando analisa uma obra de arte tende a desconsiderá-la enquanto uma totalidade, preferindo encontrar fendas e brechas que abram sempre uma possibilidade de pensamento. É nesse sentido que se pode entender essa afirmação a propósito de Hollywood dada em uma entrevista em 2014:

Dito isso, pode-se dizer também, se se olha a história de Hollywood, que ela foi também como que uma transposição popular de uma certa ideia da obra de arte total. O filme hollywoodiano tradicional, feito com diretores vindos da Europa central, formados nas escolas de arte na Europa, igualmente com operadores, uma série de cooperadores assim como diretores, operadores, cameramen, atores, que fizeram como que uma espécie de transposição para Hollywood de certo sonho estético europeu. Não o sonho de Vertov, mas o sonho de um tipo de obra de arte total, popular, onde há ao mesmo tempo a potência da história, a potência do mito, mas também a contemplação do esplendor das luzes, das sombras, e também o fato de que qualquer coisa, qualquer objeto, qualquer ser pode ser uma fonte de emoção e de grande arte. É nisso que um realizador politicamente engajado hoje como Pedro Costa pode se parecer, quando ele diz que seus mestres são pessoas como Jacques Tourneur, com realizadores hollywoodianos, uma vez que eles souberam dar a um objeto qualquer uma espécie de grandeza e deixar participar um público de pessoas comuns a esta espécie de grandeza da arte. ${ }^{3}$

Rancière nos insta a olhar um filme de Hollywood por exemplo por suas bordas a fim de encontrar ali não apenas "a potência do mito", mas também "o fato de que qualquer coisa, qualquer objeto, qualquer ser pode ser uma fonte de emoção e de grande arte".

Com esse argumento, de certa forma é possível rebater as considerações de Boris Groys a propósito do caráter propagandístico do cinema de Eisenstein. Georges Didi-Huberman vai na linha de que mesmo reconhecendo o caráter de "propaganda" do cinema de Eisenstein, é possível reconhecer o gênio do realizador nas bordas do filme. Em uma aula em um seminário dedicado à questão da lamentação em

3 HUSSAK, Pedro. Entrevista com Jacques Rancière. Dossiê Rancière. Revista Aisthe. UFRJ. V. 7, N. 11, 2013, p. 105. 
Eisenstein, o historiador da arte mostra a cena do Encouraçado dos marinheiros dormindo rede no barco na qual há claramente uma atmosfera homoerótica para responder a uma crítica feita por Pier Paolo Pasolini que considerava o cineasta russo excessivamente mecanicista na forma de apresentar os sujeitos revoltosos. ${ }^{4}$

\section{Eras do cinema}

Como foi visto, Silvia Schwarzböck identifica um caráter eminentemente estatal nos primórdios do cinema. No entanto, ela percebe no fato de que intelectuais de esquerda (entre os quais o próprio Rancière) terem se tornado cinéfilos uma ruptura importante no contexto do pós-guerra. Isso acarretou em um processo de "intelectualização" do cinema que começa com o neorrealismo italiano, passando pelos grandes movimentos do cinema nos anos 1950/60 como a Nouvelle Vague e o Cinema Novo. Com isso, a filósofa argentina propõe uma periodização do cinema: o seu momento estatal ela chama de clássico, já o período pós-guerra, é denominado de moderno. Os anos 1970, que ela caracteriza como cinema contemporâneo e a ideia de que vivemos em um mundo pós-cinema estão fora do escopo desse artigo. Cabe questionar em que medida no pós-guerra e a tentativa de vários movimentos importantes particularmente nos anos 1950/60 ao proporem uma separação entre o "cinema de arte" e o "cinema comercial" de alguma maneira não reproduzem as hierarquias entre a "alta" e a "baixa" cultura.

Para Schwarzböck, cada época do cinema forma o espectador de acordo com o modo como é estabelecida a relação entre o cinema e a realidade. Assim, o espectador do período clássico não vê os filmes como "clássicos", mas como "populares" na medida em não percebe a contradição entre o mundo cinematográfico e a vida cotidiana, e por isso ele não se sente superior ao filme que ele vê, o que permite que o cinema atue como uma arte de estado. A mudança para o cinema moderno se dá na própria formação desse espectador que conseguindo compreender a contradição que há entre o real e a linguagem fílmica consegue perceber o cinema clássico como tal. Esse processo de formação dura aproximadamente até 1960 e marca a passagem para o cinema moderno no pós-guerra. Essa mudança no modo de relação do espectador explica, por exemplo, como um cineasta de esquerda como Glauber Rocha pudesse ter sido influenciado por um autor reacionário como John

4 Essas considerações sobre Eisenstein e Pasolini foram feitas por Georges Didi-Huberman durante o seminário Peuples en larmes, peuples en armes proferido no Institut national d'histoire d'art (INHA) entre 2014 e 2015. 
Ford, não obviamente pela questão ideológica, mas pelo próprio domínio da linguagem cinematográfica.

Uma nota crítica sobre as periodizações do cinema proposta pela autora. Embora ela produza operadores bastante consistentes para entender a história do cinema, é preciso ponderar que há sempre o risco de se fazer generalizações. $\mathrm{Na}$ Fabula cinematográfica, Rancière pergunta se é possível estabelecer "eras" do cinema como é a proposta de Deleuze da passagem da imagem-movimento para a imagemtempo. Assim, embora possa concordar que na verdade nos primórdios a dimensão estatal do cinema é fundamental, é preciso também dizer que não é a única dimensão do cinema naqueles tempos. Outros experimentos cinematográficos também foram realizados, como é caso dos filmes surrealistas. Aliás, a própria autora atesta a possibilidade de outras filmografias como o expressionismo alemão quando afirma que Eisenstein para alcançar o efeito desejado não poderia fazer um filme sombrio como O Gabinete do Dr. Calighari de 1920 - que como mostrou de forma magnífica Kracauer antecipa Hitler -, pois para alcançar o efeito desejado, o filme de Eisenstein deveria primordialmente enfatizar a altivez do trabalhador que alcança suas conquistas através da luta. ${ }^{5}$

Por outro lado, embora a ideia de que o cinema forme uma determinada percepção do público ajude a entender o papel central do cinema como organização social no século $X X$, é preciso ponderar também com Rancière que aquilo que genericamente chamamos de "público" consiste em uma multiplicidade de juízos estéticos. Nesse sentido, Rancière (2008) pensa a questão do efeito que uma obra arte vai ter no espectador de "efeito estético" que é o fato de que não se pode controlar o juízo que um espectador vai formar sobre a obra de arte. Tal noção obviamente volta-se não apenas contra o teatro do século XVIII que queria fazer um tipo de construção para alcançar um efeito moralizante no espectador, como também contra Brecht para quem o dispositivo do distanciamento no teatro deveria gerar um tipo de consciência crítica no espectador. Nesse sentido, o aspecto propriamente político e democrático do juízo estético está no fato de que ele é livre e capaz de produzir discursos que por sua vez produzem uma comunidade em torno da obra.

\section{Filme de autor}

No que toca ao cinema do pós-guerra, mais uma vez Rancière (2011) e Schwarzböck adotam um ponto de partida comum, ao enfatizarem a importância do 5 SCHWARZBÖCK, Silvia. Los monstruos más frios: estética después del cine, op. cit., p. 28. 
fenômeno cultural surgido na época que conhecemos com o nome de cinefilia. Tal fenômeno é o produto direto da fundação na França da revista Cahiers du cinéma em 1951 e da influência decisiva de seu criador, o crítico André Bazin. Em torno dele, um círculo de jovens intelectuais - Godard, Chabrol, Rivette, Truffaut - começa a se interessar pela arte "popular", considerada "vulgar" por uma certa tradição intelectual das gerações anteriores ainda muito ligada a uma certa ideia da superioridade cultural da literatura sobre o cinema. Essa geração de intelectuais não se limita apenas ao âmbito da crítica como também parte para a realização de filmes, cujo conjunto ficou conhecido como a Nouvelle vague.

Interessante que a esse respeito Rancière e Schwarzböck destacam dois lados da mesma moeda: se Rancière celebra o fato de que o encontro do intelectual com a arte popular do cinema pudesse significar a superação da distinção entre "arte intelectualizada" e "arte popular", a autora argentina considera justamente que a Nouvelle Vague "intelectualizou" o que antes fora uma arte popular. Daí uma distinção que ainda hoje costumamos ouvir, que no fundo reproduz a distinção adorniana entre arte autônoma e indústria cultural, entre o cinema de autor ou de arte e cinema comercial.

Nesse ponto, as considerações de Schwarzböck podem proporcionar uma ponderação com referência à posição de Rancière. Será que toda a tradição, que se pode de uma maneira geral relacionar à Nouvelle Vague, que busca fazer um "cinema de arte", consegue efetivamente superar as hierarquias supramencionadas do gosto. É comum ouvir a crítica de que mesmo um movimento com o Cinema Novo brasileiro não conseguiu o objetivo de atingir as parcelas populares, restando restrito a uma intelectualidade de esquerda.

Nesse sentido, talvez as considerações de Schwarzböck possam ser ocasião para uma ponderação em relação a Jacques Rancière, pois embora ele mencione realizadores "populares" como Chaplin e Minelli, seus escritos mobilizam preferencialmente nomes como Bela Tarr, Pedro Costa, Abbas Kierostami, Straub \& Huillet, e a menos que concordemos com Pedro Costa, quando ao responder o que entende por cinema popular responde Godard e Straub \& Huillet, trata-se notadamente de uma constelação de autores "intelectualizados" e de difícil apreensão pelo grande público. 


\section{Conclusão}

Abordei o tema do espectador no cinema a partir de perspectiva filosófica buscando contrapor duas visões. Embora a filiação às concepções de Jacques Rancière esteja patente, isso não significa que o objetivo aqui seja o de desconsiderar as posições de Schwarzböck. Ao contrário, como pretendi mostrar, a autora demonstra enorme vitalidade intelectual ao explicitar de forma magnífica a força dessa expressão cultural que é o cinema. Quando propõe uma periodização - o cinema clássico, o moderno e o contemporâneo -, Schwarzböck monta um esquema interpretativo que nos ajuda a vislumbrar qual tanto o significado político do cinema no desenrolar do século XX, quanto apontar para a compreensão da nossa realidade contemporânea pós-cinema.

As ponderações colocadas buscam abrir algumas brechas na leitura buscando sempre apontar em que sentido sempre é difícil falar em um "público" entendido como uma unidade. É nesse sentido, que mobilizamos a noção de efeito estético em Jacques Rancière para apontar a impossibilidade de se controlar o que o espectador vai compreender de um filme.

Por outro lado, a confrontação com a autora argentina levou-me também a estabelecer uma crítica a Jacques Rancière cujo pensamento está imbuído pelo projeto de estabelecer as condições para se colocar a questão da democratização da cultura. A favor de Rancière, pode-se dizer que, embora as escolhas supracitadas dos cineastas a serem analisados possa sugerir um elitismo cultural, elas também impõem um desafio para todo intelectual e amante do cinema. Para Rancière, a questão da "partilha do sensível" concerne à ideia de que não é por "falta de capacidade" que alguém não entende um filme, o que coloca um problema com relação à possibilidade da circulação de filmes como, por exemplo, os do cineasta Pedro Costa. Assim, se Rancière é um crítico do intelectualismo, tanto do ponto de vista estético quanto político, enquanto um dirigismo em relação a quem supostamente "não tem a capacidade" de compreender um filme, isso não significa, a meu ver, que ele retire completamente um papel decisivo para os intelectuais como agentes culturais. Tratase não de explicar os filmes "intelectualizados", mas, valendo-se das facilidades técnicas dos atuais dispositivos audiovisuais, de exibi-los e a partir disso promover debates nos quais os juízos possam circular livremente.

Minha abordagem iniciou com um problema que vem desde o século XVIII a respeito da hierarquização entre a "alta" e a "baixa" cultura, mostrei como o cinema no 
pedro hussak van velthen ramos | dentro da sala escura

século $X X$ de alguma forma problematizou essa divisão, ao mesmo tempo que levantou problemas novos em relação à questão do espectador. Obviamente meu objetivo não é dar uma resposta conclusiva, mas o de abrir caminhos para um debate na medida em que o desafio pela democratização da cultura continua nos dias atuais. 


\section{Referências Bibliográficas}

ADORNO, Theodor; HORKHEIMER, Max. Dialética do esclarecimento. Trad. Guido de Almeida. Rio de Janeiro: Zahar, 1985. [1947].

GROYS, Boris. Obra de arte total Stalin. Trad. Desiderio Navarro. Valencia: Pre-textos, 2008.

HUME, David. Investigação acerca do entendimento humano - ensaios morais, políticos e literários. São Paulo: Nova Cultural, 1999. (Coleção “Os Pensadores").

KANT, Immanuel. Crítica da faculdade do juízo. Trad. Valério Rohden. São Paulo: Forense, 1995.

RANCIĖRE, Jacques. Les écarts du cinema. Paris, Fabrique, 2011. . A Fábula cinematográfica. São Paulo, Papirus, 2013. Le spectateur émancipé. Paris: Fabrique, 2008. La Nuit des prolétaires. Paris: Fayard, 1981.

O Mestre ignorante. Trad. Lílian do Vale. $3^{a}$. Rio de Janeiro:

Autêntica, 2007. [1987].

SCHILLER, Friedrich. A educação estética do homem. Trad. Marcio Suziki. 4ª. ed. São Paulo: lluminuras, 1995.

SCHWARZBÖCK, Silvia. Los monstruos más frios: estética después del cine. Buenos Aires: Mardulce, 2017.

ŽlŽEK, Slavoj. Lacrimae Rerum. Ensaios Sobre Cinema Moderno. São Paulo: Boitempo, 2018. 